\title{
What is Ground Water?
}

\section{How does water get into the ground?}

When rain falls to the ground, the water does not stop moving. Some of it flows along the land surface to streams or lakes, some is used by plants, some evaporates and returns to the atmosphere, and some seeps into the ground. Water seeps into the ground much like a glass of water poured onto a pile of sand.

As water seeps into the ground, some of it clings to particles of soil or to roots of plants just below the land surface. This moisture provides plants with the water they need to grow. Water not used by plants moves deeper into the ground. The water moves downward through empty spaces or cracks in the soil, sand, or rocks until it reaches a layer of rock through which water cannot easily move. The water then fills the empty spaces and cracks above that layer. The top of the water in the soil, sand, or rocks is called the water table and the water that fills the empty spaces and cracks is called ground water.

Water seeping down from the land surface adds to the ground water and is called recharge water. Ground water is recharged from rain water and snowmelt or from water that leaks through the bottom of some lakes and rivers. Ground water also can be recharged when watersupply systems (pipelines and canals) leak and when crops are irrigated with more water than the plants can use.

At least some ground water can be found almost everywhere. The water table may be deep, such as under a hillside, or shallow such as under a valley. The water table may rise or fall depending on several factors. Heavy rains or melting snow may increase recharge and cause the water table to rise. An extended period of dry weather may decrease recharge and cause the water table to fall.

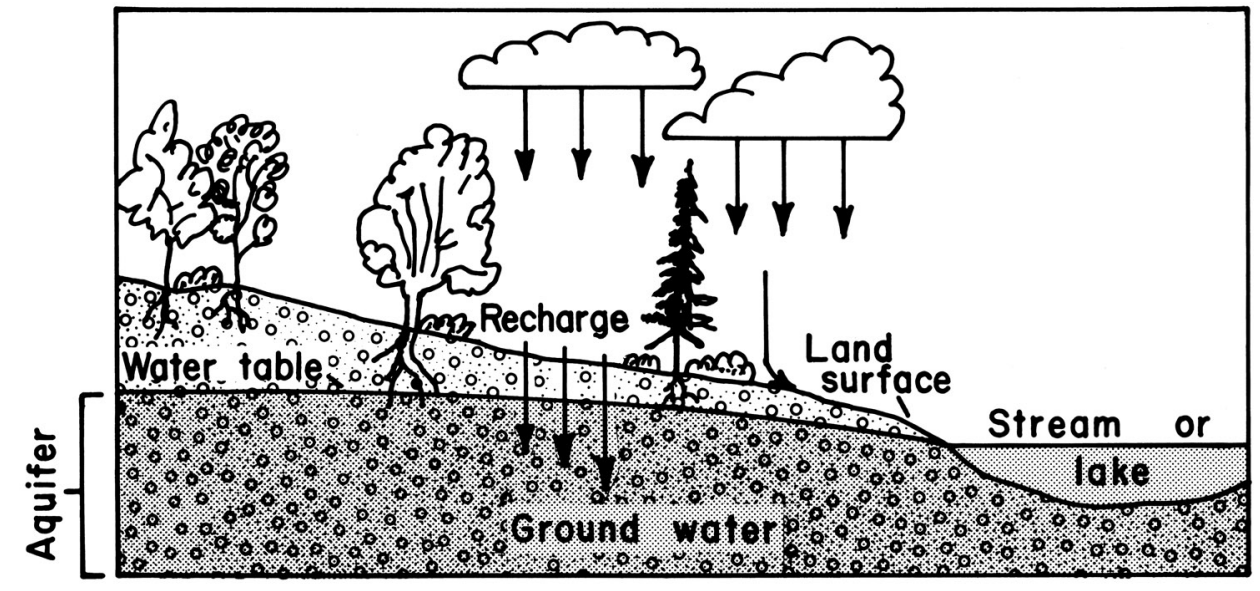

\section{What is an aquifer?}

Aquifer is the name given to underground soil or rock through which ground water can easily move. The amount of ground water that can flow through soil or rock depends on the size of the spaces in the soil or rock and how well the spaces are connected. The amount of spaces is the porosity. Permeability is a measure of how well the spaces are connected.

Aquifers typically consist of gravel, sand, sandstone, or fractured rock such as limestone. These types of materials are permeable because they have large connected spaces that allow water to flow through. The spaces in a gravel aquifer are called pores. The spaces in a fractured rock aquifer are called fractures. If a material contains pores that are not connected, ground water cannot move from one space to another. These materials are said to be impermeable. Materials such as clay or shale have many small pores, but the pores are not well connected. Therefore, clay or shale usually restrict the flow of ground water. The next illustration shows how the connections between the pores or fractures control how water moves through an aquifer.

\section{Who uses ground water?}

More than 50 percent of the people in the United States, including almost everyone who lives in rural areas, use ground water for drinking and other household uses. Ground water is also used in some way by about 75 percent of cities and by many factories. The largest use of ground water is to irrigate crops.

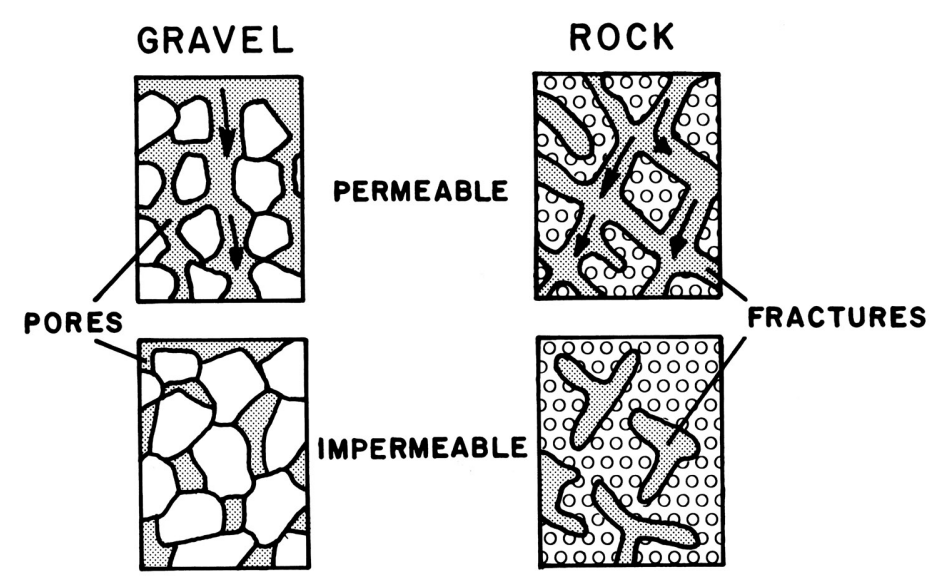




\section{How do you get water out of the ground?}

Ground water can be obtained by drilling or digging wells. A well is usually a pipe in the ground that fills with ground water. This water can then be brought to the land surface by a pump. Shallow wells may go dry if the water table falls below the bottom of the well, as illustrated at right.

Water leaving an aquifer is called discharge water. Water that is pumped from a well is discharge water. Ground water might also discharge naturally as springs or into swamps, lakes, or rivers.

Some wells, called artesian wells, do not need a pump. These wells are drilled into an artesian aquifer, which is sandwiched between two impermeable layers. Water enters an artesian aquifer in a permeable recharge zone, which can be miles away from the well. When a well is drilled into an artesian aquifer, pressure pushes water in the well above the top of the aquifer. If the pressure is high enough, water can flow from an artesian well.
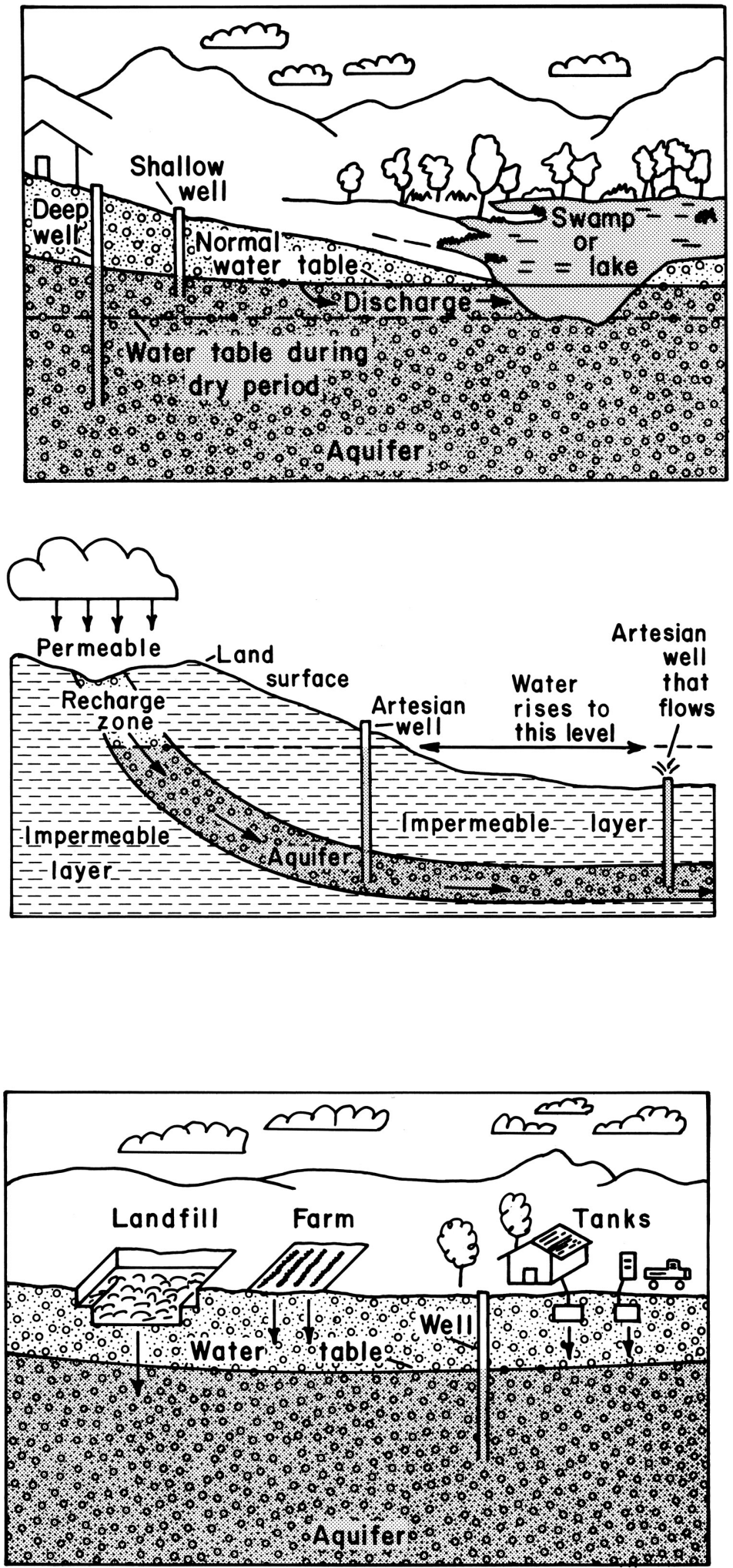

For additional information, please contact:

U.S. Geological Survey

Water Resources Division

Chief, Office of Ground Water

12201 Sunrise Valley Dr.

Reston VA 20192

Telephone: (703) 648-5035 FAX: (703) 648-5722

http://water.usgs.gov/ogw/index.html 